\title{
DESCRIPTION OF A METHOD OF TAKING OFF THE WASTE GASES FROM BLAST FURNACES.
}

\author{
By Mr. CHaRles cochrane, of Middlesborodga.
}

There is no novelty in the fact of Taking Off the Waste Gases from a blast furnace; for many methods have been and are at present employed for accomplishing this object. Though the writer was unaware of any similar method, it is not desired to claim originality in that about to be described; but as there is such acknowledged diversity of opinion as to the respective merits of different plans, and great difficulty in procuring reliable information on any, it is proposed to give a description of an arrangement which has been in successful operation for some months at the Ormesby Iron Works, Middlesborough, and bids fair to realise the best expectations of its merits. The large waste of fuel from the mouth of a blast furnace where the escaping gases are allowed to burn away is well known, and amounts to more than 50 per cent: of the fuel burnt; hence there is considerable margin for economy, bearing in mind the large quantity of coals consumed in raising steam for generating the blast and the further quantity necessary to heat that blast to the required temperature. In fact assuming a consumption of 300 tons of coke per week to maka 200 tons of iron, about 100 tons of coals would be required to generate steam and heat the blast. Taking off the gases from one furnace under such conditions does according to actual experiment furnish gas equivalent to upwards of 150 tons of coal per week. This is obviously an important matter where coals are expensive.

The blast furnace is alternately charged with coke, ironstone, and limestone, in proportions depending upon the quality or "number" of iron desired. The arrangement of these materials in the furnace is generally deemed important, though it admits of considerable latitude without any appreciable alteration in the working of the furnace. 
Thus it does not seem to be of any importance whether the charge of coke be 12 cwts. or $24 \mathrm{cwts}$, the amount of load of ironstone and limestone being in the same proportion of 1 to 2 . The chief point, if there be one, to be gained in the arrangement of the material is to distribute it pretty equally over the furnace, not allowing all the large material to roll outwards and the small to occupy the centre of the furnace or vice versâ : for it is supposed the ascending gases will pass through the more open material of the furnace to the injury of the closer; thus the two reach the active region of reduction in different states of preparation, and the operations of the furnace are interfered with. To provide for this contingency, which is met in an opentopped furnace by filling at the sides at three, four, or even six points of the circumference of the throat, allowing the material to slide inwards 2 or 3 feet on a sloping plate, it was considered expedient in the present instance to make the filling aperture as large as practicable: it was therefore made 6 feet 6 inches diameter, as shown in Fig. 1, Plate 24, so that the material tends to arrange itself in a circle a little outside the centre, thas correcting the tendency of large material to roll outwards by causing a similar tendency to roll towards the centre also. This point is gained in one of the simplest methods in use for closing the top of a blast furnace, where a cone is used to lower into the furnace for filling; but it is secured at the expense of the height of material in the furnace. A certain height is necessary for the efficient working of the furnace, and if this be diminished it must be at the expense of fuel in the furnace, since the absorption of heat from the gases depends on the height of material through which they have to pass up: if this be diminished, the gases issuing from the throat of the furnace will escape at a higher temperature; if increased, at a lower.

But there is an important difference to consider in the conditions of a closed and an open-topped furnace, to which the writer is not aware that attention has hitherto been drawn; a differenee which acts somewhat in favour of the open-topped furnace. The working of the furnaces themselves seems to show that an open-topped furnace is less sensitive to irregularities of moisture in the material, quantity of limestone, size of material, \&c.; which ean be accounted for only by 
the fact that the open-topped furnace has the advantage of a large amount of surplus heat due to the combustion of the waste gases at * its throat, which serves to dispel moisture and calcine the limestone and helps to warm up the large pieces of ironstone: all of which operations in the close-topped furnace are effected only at a lower point of the furnace, thus neeessitating a larger consumption of coke. With the same proportion of ironstone to limestone it has been found to require about 10 per cent. more fuel to produce the same number or quality of iron in a close-topped than in an open-topped furnace. In the close-topped furnace the gases pass away at a temperature of about $450^{\circ}$ Fahr.; whilst in the open-topped a temperature of between $1000^{\circ}$ and $2000^{\circ}$ is generated in the throat of the furnace by their combustion.

In comparing the extra quantity of coke consumed in a closetopped blast furnace with the saving in coals for the boilers and hot-blast stoves, it is obvious that the economy to be derived by taking the gases off depends on the comparative value of coke and coal. In the Middlesborough district where coal is expensive, it is an undoubted source of economy; where coke is very dear bowever and small coal can be abtained at a mere nominal cost for boiler and stove purposes, the use of the waste gases would possibly do little more than eompensate for the outlay involved. Here no. doubt is one source of the variety of opinion entertained in rarious districts as to the advantage of taking off the gas. The writer's experience at Middlesborough has been that the waste gases can be taken off without affecting the quality of the iron produced, though at the expense of more fuel.

The mode of closing the furnace top and taking off the gases at the writer's works is shown in Fig. 1, Plate 24. The top of the furnace is closed by a light circular wronght iron valve $A, 6$ feet 6 inches diameter, with sides tapering slightly outwards from below, as shown enlarged in Fig. 2, Plate 25, to admit of being easily drawn up through the materials, which are tipped at each charge into the external space B. To prevent excessive wear upon the body of the valve, shield plates are attached at four points of its circumference, 
against which the material strikes as it rolls out of the barrows. An annular chamber $\mathrm{C}$ encircles the throat, triangular in section, into which the gas pours through the eight orifices DD from the interior of the furnace, and thence passes along the rectangular tube $\mathbf{E}$ into the chamber F. At the extremity of the tube $\mathrm{E}$ is placed an ordinary flap valve opened by a chain, by means of which the communication between the furnace and the descending gas main $G$ may be closed. The valve $A$ is partially counterpoised by the balance weight at the other extremity of the lever $\mathrm{H}$, and is opened by a winch $I$ when the space $B$ is sufficiently full of materials. At the time when the blast is shut off for tapping the furnace, the gas eseapes direct into the atmosphere through the ventilating tube $K$, which is connected by levers $L$ with the blast inlet valve below.

Fig. 5, Plate 26, shows the connexion between the furnace top and the hot-blast stoves to be heated by the waste gases, which pass down the descending main $G$ into the horizontal main $M$ running parallel and close to the line of stoves $N$, from which descend smaller pipes $O$ to each stove, as shown in Figs. 3 and 4 . The supply of air for burning the gas in the stoves is admitted through the three tubes $\mathrm{P}$, and can be regulated at pleasure by the circular slide closing the ends of the tubes, which has an aperture corresponding to each tube, and is planed on the rubbing face, as is also the surface against which it works, in order that the slide may be sufficiently air-tight when closed. The ignition takes place where the air and gas meet, the ignited gas streaming into the stove and diffusing its heat uniformly over the interior. An important element in the working of an apparatus of this description is to provide for explosions, which must take place if a mixture of gas and air in certain proportions is ignited. To propide for this contingency, escape valves $R$ are placed at the ends and along the tops of the main tubes $\mathbf{G}$ and $\mathbf{M}$ : but to prevent explosions as far as possible, the ventilating tube $K$, Fig. 1 , is used at the top of the furnace, connected with the blast valve at the bottom so that when the valve is closed, as at casting time, the act of closing opens the ventilating tube and allows the gas to pass away direct into the atmosphere. The gas would otherwise be in danger of slowly mixing with air passing back through the stoves or otherwise gaining 
access into the tubes, and would thus give rise to an explosion; until the ventilating tube was provided, it was necessary to lift the valve $\mathbf{A}$ closing the mouth of the furnace when the blast was taken off, otherwise slight explosions took place from time to time.

In the use of Durham cokes in the blast furnace an inconvenience arises from the large deposit which takes place in the passage of the gas from the furnace and in the stoves and boilers. Under the boilers this deposit is a great objection, as it is a very bad conductor of heat and needs to be frequently removed: in the stoves it is not so objectionable, though these need a periodical cleansing. The deposit does not arise altogether from the cokes, it is true; and it may be interesting to know its composition which is as follows :-

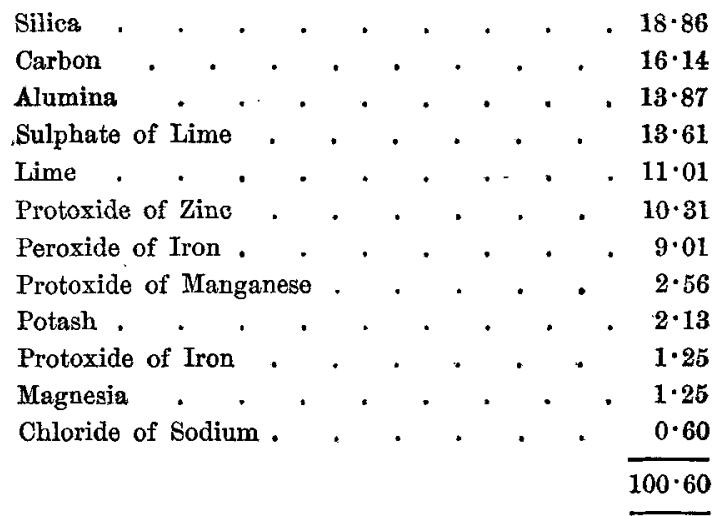

At a temperature of upwards of $3000^{\circ}$ this mixture melts in a yellowish slag, dispelling the zinc; but there are no signs of fusion at the temperature produced by the ignition of the gas in the stoves, which must roughly approximate to that of melting iron from the results of a few experiments made to ascertain this point: though thin pieces of cast iron were not fairly melted down, they reached the rotten temperature, which is only a few degrees belo melting, and gave further signs of nearly melting by throwing of aparks when quickly withdrawn from the stoves and struck smartly against another object. 
The writer has heard it asserted that the closing of the top of the furnace is the source of mischief to its working by producing a back pressure in it. Under ordinary circumstances, with the furnace top open, the blast enters the tuyeres at a pressure ranging from $2 \frac{1}{2}$ to 3 lbs. per square inch. In the present close-topped furnace there are eight ontlet orifices D, Fig. 1, each 2 feet by 1 foot, giving a total area of 16 square feet for the passage of between 5000 and 6000 cubic feet of gas per minute raised to a temperature of $450^{\circ}$ Fahr.; and the actual back pressure of the gas as measured by a water gauge inserted into the closed top of furnace is from $\frac{1}{2}$ to $\frac{5}{8}$ inch column of water, or about 1-40th or 1-50th of a pound per square inch, an amount so trivial as compared with a pressure of from $2 \frac{1}{2}$ to 3 lbs. as to be unworthy of notice. Of course if the tubes are contracted in size a greater back pressure will be produced; and it is quite possible that, where attention has not been paid to the circumstance, the back pressure may have interfered with the working of the furnace by preventing the blast entering so freely.

As regards economy in the wear and tear of hot-blast stoves of the ordinary construction, there can be no question the pipes last much longer when heated by gas, provided the temperature of the stove be carefully watched to prevent its rising too high; whilst the value of the same heating surface compared with its valne when coals are used is greatly increased, owing to the uniform distribution of the ignited gases throughout the stove: in the use of the gases at the writer's works, this economy of surface is such that two stoves heated by gas will do the work of a little more than three heated by coal fires.

Mr. W. Mathews considered the subject of economising the waste gases from blast furnaces was one of much importance, and was glad it had been so ably taken up in the paper just read. He asked whether there was found to be any material difference in the working of the close-topped furnace, and whether the closing of the top for 
the purpose of taking off the gases interfered with the burden of the furnace or the quality of iron prodaced. If the quality and yield of iron were not disturbed, the utilisation of the waste gases must be a source of economy where fuel was dear ; but otherwise, where coals were cheap, it might hardly be worth while putting up an apparatus for taking off the gases. In the case of some blast furnaces lately erected at Heyford in Northamptonshire, where the ore was cheap but coal expensive, costing 148. or 15s. per ton at the furnaces, the iron could not have been worked profitably unless the waste gases were taken off; this had accordingly been done, and he understood had proved thoroughly successful, reducing the cost of making the iron greatly. It seemed remarkable that the use of the waste gases was not yet adopted in South Staffordshire; but this was no doubt owing to the extreme cheapness of small cool throughout the distriet, as compared with the North of England, so that it might not bo economical to take off the gases. At Dundyvan in Scotland a method had been employed some years ago for taking off the gases without closing the top of the furnace, and the gases were used for the hot-blast ovens and engine boilers : but the heat obtained vary irregular, sometimes high and sometimes low, causing much difficulty in keeping up the temperature of blast and in getting the required supply of steam; and he understood the plan had reeently been discontinued there on account of the trouble experienced in its roge.

Mr. C. Cochane replied that the regularity of the farnae nas certainly interfered with, though only to a slight extent, by closing the top, and the furnace was rendered more sensitive. In the first trials of the close-topped furnace mottled iron was made frequently, and occasionally white iron; but by exercising sufficient care in managing the furnace the irregularities were now in a great measure got over. During the last six months his furnace had worked with only. 7 par cent. irregularity altogether, and this was now reduced to 5 per cent, estimating the amount of irregularity by the proportion of mottled iron made instead of grey. Where it would be an objection to make mottled or white iron occasionally, it wauld not be advisable to tw taking off the gases; and coals were so cheap in South Staffordshire that it might not be worth while to run the risk of getting white 
iron, as it was of more importance there to make all grey iron than in the Middlesborough distriet, where there was a greater demand for forge iron.

Mr. C. Markham had been connected with some blast furnaces at Marquise in the north of France fourteen years ago, from which the waste gases were taken off very successfully; and thought the mode of carrying out the plan in that case was superior, owing to the gases being conveyed upwards to a higher level to be burnt, as they would naturally rise by reason of their specific gravity being less than that of the atmosphere. There were two furnaces built side by side against a bank, and the gases were taken off about 5 or 6 feet below the top by a circular flue running all round the furnace; they were taken under six Cornish boilers situated at the top of the bank, a few feet above the top of the furnace. The gases were drawn off from the furnaces by a chimney 90 feet high, and they frequently produced a large flame from the top of the chimney. The evil of the gases firing subsequently to passing under the boilers was removed to a considerable extent by the erection of an additional flue, which caused the gases to be more perfectly mixed with air and fired before they were cooled down by coming in contact with the boilers. The regular make of each furnace was 100 to 120 tons of cold-blast iron per week, and the consumption of coke was about $1 \frac{1}{2}$ tons per ton of iron made. The coke cost $30 \mathrm{~s}$. per ton, so that economy of fuel was of great importance; the boilers were worked entirely by the waste gases from the furnaces. At these furnaces they had tried at first bringing the gases downwards to the boilers at a lower level, but the success was very imperfect; and this appeared to him the reason why the waste gases had not been taken off so successfully at some works in this country, as they had in every case he believed been conveyed downwards from the top of the furnace instead of upwards, and also the height of the furnace had not been increased to compensate for the gases being taken off at a lower level. He had seen the application of the gas at the Clay Cross and Alfreton furnaces in Derbyshire, and had no doubt an economy was effected in the cost of the iron made: at these works however the gas was applied only for heating the hot-blast stoves, but the quantity required to heat the blast was small as 
compared with that required to raise a sufficient supply of steam for working the blast engine.

Mr. C. Cochrane said no difficulty had been experienced in bringing the gases down, and the vacuum required was found by actual measurement to be only $\frac{1}{2}$ to $\frac{5}{8}$ inch column of water, or 1-40th lb. per square inch, which was not sufficient to produce any injurious effect on the working of the furnace.

Mr. C. W. Siemers had seen furnaces working at Charleroi in Belgium where the gases were drawn down from the top of the furnace without any difficulty, by means of a pipe inserted in the side of the furnace near the top; but it was found necessary to allow at least one third of the gas to burn out of the mouth of the furnace, otherwise the working of the furnace was interfered with, and neither was the iron of such good quality nor the gas so effective for heating purposes. In the close-topped furnace at Middlesborough described in the paper he suggested whether any difference of make or irregularity of working was not rather to be attributed to imperfect distribution of the materials in charging, than to closing the top; with a closed top and an arrangement for filling in the centre, as shown in the drawings, there was no means of filling at the sides of the furnace, and the materials might roll sometimes more to one side than the other, producing a greater draught through the furnace in one direction; so that the ore would arrive at the point of reduction in different states of preparation, which would interfere with the quality of iron made. A slight difference was sufficient to direct the flame and current of gas in a blast furnace more to one side than another : even in drawing off the gases by a circular chamber all round the furnace, the draught holes on the side nearest the main flue would draw more than those on the opposite side; but this might be obviated by making the holes nearest the flue of a smaller size.

Mr. Samozi Lloyd said they had now adopted a plan for taking off the waste gases at the Old Park furnaces, and had had it working there successfully for some weeks, without any injury being caused to the working of the furnace; the iron seemed if anything to be rather better in quality, a little more grey, and somewhat increased in quantity. The plan was that of Mr. Darby of Brymbo in North Wales, where it 
had been at work successfully for two years past; it consisted of a plain upright tube inserted into the centre of the open mouth of the furnace, and then carried over down the outside of the furnace, where the gas was burned under the steam boilers, the flues of which were connected with a sufficiently tall chimney to produce a draught for drawing down the gas. The large area between the tube of 5 feet diameter and the mouth of the furnace of 10 feet diameter was left open, so that there was no pressure on the furnace, which worked in that respect exactly like an open-topped furnace. The tube was inserted about 5 feet deep into the materials at the top of the furnace, and by this means they got four boilers heated by gas without any cost for fuel. He thought this plan of leaving a large portion of the furnace top open was the only practicable way of taking off the waste gases in the South Staffordshire district, where it was of the first importance that grey iron should be made, and considered it was a great improvement on the close-topped system : for the open top of the furnace allowed the extra quantity of gas to escape direct into the atmosphere; but with a closed top the top of the furnace was choked, and the accumulation of gas was liable to produce a back pressure on the furnace, which they had found by experience was very injurious.

Mr. E. A. Cowpen had seen the furnace at the Ormesby Works, and thought the arrangement there employed for filling produced a good distribution of the materials. The plan of closing the furnace top by a cast iron cone or bell inside the furnace, fitting up against a cast iron ring or seat, was a good arrangement when properly carried out, as at Ebbw Vale; thongh in some cases, where the cone had not been properly proportioned to the size of the furnace, an unequal distribution of the materials took place, the smaller pieces lying in a heap in the centre, while the larger ones rolled down to the sides of the furnace, causing a stronger draught up the sides than at the eentre; and in large-topped furnaces where the charging cone was of small size, the sides thus became much hotter than the middle of the furnace. But in the arrangement shown in the drawings this difficulty was got over by making the charging opening not less than half the diameter of the top of the furnace, the effect of which was that the larger pieces now rolled towards the centre as well as the 
sides, so that there was as strong a draught up the centre as at the sides, and the heat was rendered more uniform. He believed that the regular working of a furnace depended quite as much upon the materials being nearly of a uniform small size as on anything else, and that sufficient attention was not generally given to this point. The simple fact of closing the top of the furnace or leaving it open could not he thought cause any appreciable difference in the working of the furnace; for the ordinary pressure of the atmosphere on an opentopped furnace varied far more than the increase of pressure caused by closing the top and drawing off the gas by the draught of a chimney, as this was shown to amount to only inch column of water, or only 1-24th inch rise of the barometer. If a closed top were inadmissible for a furnace from some other cause, then such a plan as Mr. Darby's might be adopted for taking off a portion of the gas; but a high chimney would be necessary to draw the gas off through the tube, and care must be taken to keep the mouth of the tube always covered up for some depth by the material in the furnace, to prevent the risk of drawing in atmospheric air ; the tube would he thought be troublesome to keep in repair on account of the great heat to which it was exposed, and with its end buried 5 feet deep in the material would not last many weeks.

Mr. A. B. Cochrane was glad to hear of an instance of the waste gases being taken off successfully in the South Staffordshire district, as their use would effect an important saving of fuel for the steam boilers and hot-blast ovens, if it could be satisfactorily carried out; for though at present there was an abundance of cheap small coal, it had been pointed out that the time was drawing near when the Thick coal would be exhausted in the parts now worked, and it was therefore as necessary to economise the consumption in that district as in the North of England. He hoped the plan that had been referred to would be described more fully, with the results obtained as to cost and economy of fuel, that it might be satisfactorily determined whether such a method was applicable without injury to the quality of iron made.

Mr. J. E. SwINDELL asked what distance the gases could be conveyed from the furnace for being burnt for heating purposes. 
Mr. E. A. CowPer replied that the gases could be carried a great distance, several hundred yards even, before being burnt, as the slight pressure in the top of the furnace was quite sufficient. When taken off from a close-topped furnace, they came off at the comparatively low temperature of about $400^{\circ}$, and would lose only $50^{\circ}$ to $100^{\circ}$ within moderate distances.

Mr. Sampson Lloyd had tried the plan of taking off the gases by a closed top and charging cone several years ago at the Old Park furnaces, on the method adopted in South Wales that had been mentioned, but it was finally abandoned, as the furnace could not be got to work satisfactorily; and they were about to take down the pipes used for conveying away the gases, when he heard of the plan employed at the Brymbo Works, which seemed fully to meet the difficulty of avoiding any interference with the working of the furnace, and an apparatus of that kind was accordingly put up. They had several difficulties to encounter in the first attempts at getting the plan to work; and the end of the tube was melted off in consequence of reaching too far down into the hot part of the furnace. But all objections seemed now to have been got over, and they had had the plan at work nearly a month with most satisfactory results: the furnace worked better, and brought down the iron more quickly; it only required a little management when standing, to prevent the portion of the tube in the furnace getting injured.

Mr. C. Markham observed that there must be still a great waste of gas escaping through the open space round the centre tube, when the top of the furnace was not entirely closed. Even in close-topped furnaces fitted with a cone a considerable leakage of gas took place round the joint of the cone, and when the furnace was being charged; and in the arrangement shown in the drawing he thought the leakage at the joint would be much increased by the large diameter of the top valve.

Mr. E. A. Cowper said the valve had a very good joint, as it was made with a cast iron rim at the bottom, having a spherical bearing surface, so as to drop always fairly into its seat like a ball valve, and the seat was a strong cast iron ring, to ensure keeping its shape; the valve closed remarkably tight when lowered into its seat, scarcely a trace of leakage being perceptible at the joint. 
Mr. T. Sxowbow thought in working with close-topped fümaces for taking off the gases a great deal depended on having a sufficient height of chimney to ensure drawing off the gas with regularity; if the chimney were only as high as the furnace, the two columns of gas would balance each other and there would be no power of draught. The draught required however seemed to vary much in different furnaces; for in the Clay Lane furnaces at Eston near Middlesborongh the chimney was only a few feet above the top of the furnace, but produced quite draught enough, while he had seen other furnaces with higher chimneys that were not working well. At his own furnaces at Middlesborough he would have preferred placing the boilers and hot-blast stoves at the top of the furnace if it could have been done, in order to take the gases direct to them; but this was not practicable, and the gases were therefore drawn down from the top of the farnace by a chimney 120 feet high and 8 feet square, having 64 square feet area of draught. The temperature and nature of the gases taken off depended greatly on the burden of the furnace, according to the quality of ironstone that was being worked : with a heary charge of limestone the gas would not burn without great difficulty, owing to the carbonic acid gas mixed with it; and he had noticed that when the gases were best for burning, the temperature was so low in the top of the furnace that the materials were quite damp, and a long rod thrust in was drawn out covered with moisture. The gases ought never to be taken off hot through the tubes, if it could be avoided; and at Valenciennes in France some of the best working furnaces he had seen were quite cool at the top, the gases being entirely taken off and the tops closed. He was so confident of the practicability of using the waste gases that no provision had been made for a fire in the hot-blast stoves at his own works, intending to use gas entirely for heating them; but they had to put in a fire at first on starting the furnaces, though it was now used very little, and mainly at the time of starting. Some of the boilers were working without any coal fire, being heated entirely by gas ; and the total quantity of coal used both for boilers and hotblast stoves was less than $1 \frac{1}{\mathrm{cwt}}$. per ton of iron made: the coal was a mixture of small coal and slack, costing only 48 . per ton. The use of gas saved the attendance of men for firing under the boilers and stoves. 
Mr. C. Cochrane enquired what amount of irregularity had been experienced in the working of the elose-topped furnaces. At the Ormesby Works he had found that for making the same quality of iron only 7 per cent. more coke was required during six months with the close-topped furnace than had previously been consumed in the same furnace before the gas apparatus was employed. But under the best circumstances irregularities would occur, arising sometimes from the level of the materials in the furnace being allowed to go down a few feet, from want of attention in charging, so that the materials did not get so thoroughly prepared before sinking to the point of reduction in the furnace; and there was more liability of this occurring in closetopped furnaces than in open ones, from the difficulty of seeing in to observe the level. He had found his furnaces would sometimes turn round suddenly to white iron for a short time, and then return to grey iron; this was not of much consequence in the North of England, where white or mottled iron could easily be disposed of, but that was not the case in South Staffordshire.

Mr. T. SNow Don replied that change of weather and difference in the ironstone were the chief causes of fluctuations in the quality of iron and yield of the furnace; but he could not say that any material irregularity had resulted from taking off the gases. The iron produced from the close-topped furnaces appeared rather superior in quality, darker and with larger crystals; and he had never found the furnace drop off from grey iron to mottled or white. In close-topped furnaces the materials at the top were not exposed to differences of dry or wet weather as in open-topped furnaces; his own furnaces had the top closed by a cylinder and charging cone, like that at Ebbw Vale, and were charged with a whole wagon load of $36 \mathrm{cwts}$. at once tipped direct into the furnace, so that there was no irregularity in flling, and a saring of labour compared with charging by barrows.

Mr. D. Adamson observed that if there were much variation in the temperature of the gases coming off from the furnace it would affect the draught produced by the chimney, and so might influence the working of the furnace: for when the furnace was so cool at the top as to be damp, the chimney would cause an increased dranght and augment the current through the furnace; while a high temperature of 
the gases in the top of the furnace would partly counterbalance the heated column in the chimney and the draught would be diminished. Care should be taken to have the firegrates under the boilers and stoves closed air-tight, to prevent any air entering to impair the draught; and also to have a sufficiently high chimney to avoid any pressure of $\mathrm{gas}$ in the closed top of the furnace. If the chimney were large enough he could not see any reason why closing the top and taking off the gases should interfere with the proper working of the furnace; and thought there would even be an advantage in a close-topped furnace, by the pressure being relieved below that of the atmosphere, ensuring a more active condition in the furnace under all circumstances.

The Chairman proposed a vote of thanks to Mr. Cochrane for his paper, which was passed.

The following paper was then read :- 
Fig. 1.

Vertical Section

of Alosed Top

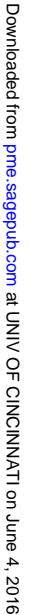

of Blast Furnace.
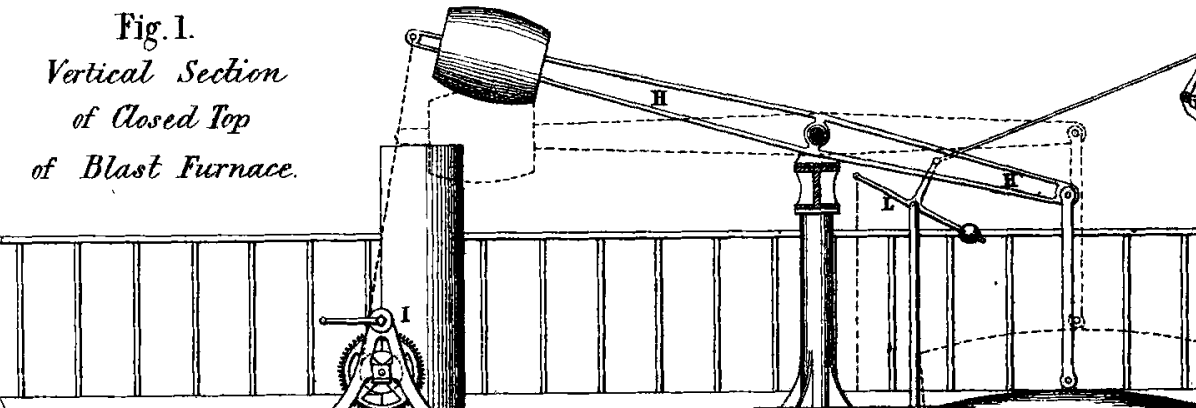

7
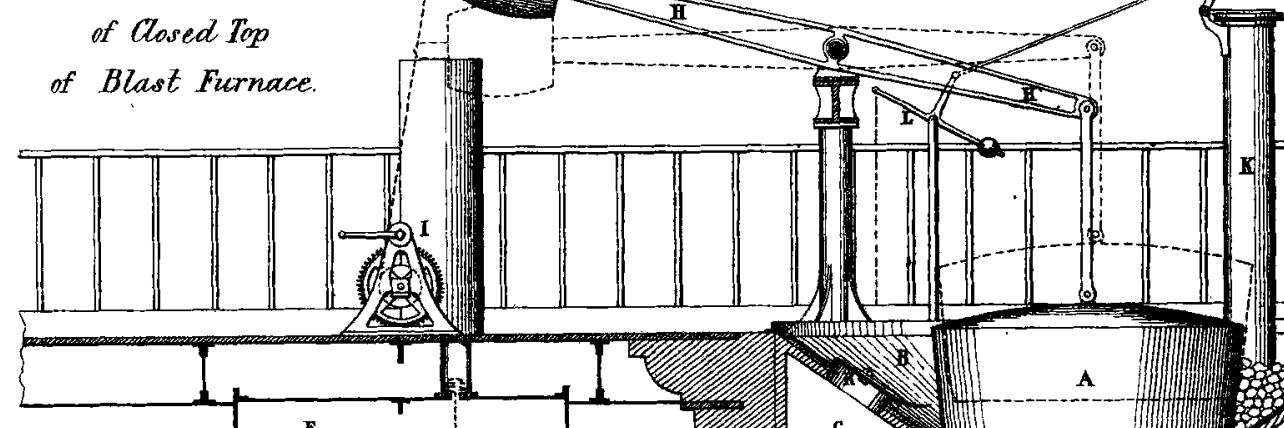
Gas Pipes to Hot-Blast stoves. Fig. 3. Fig. 4.

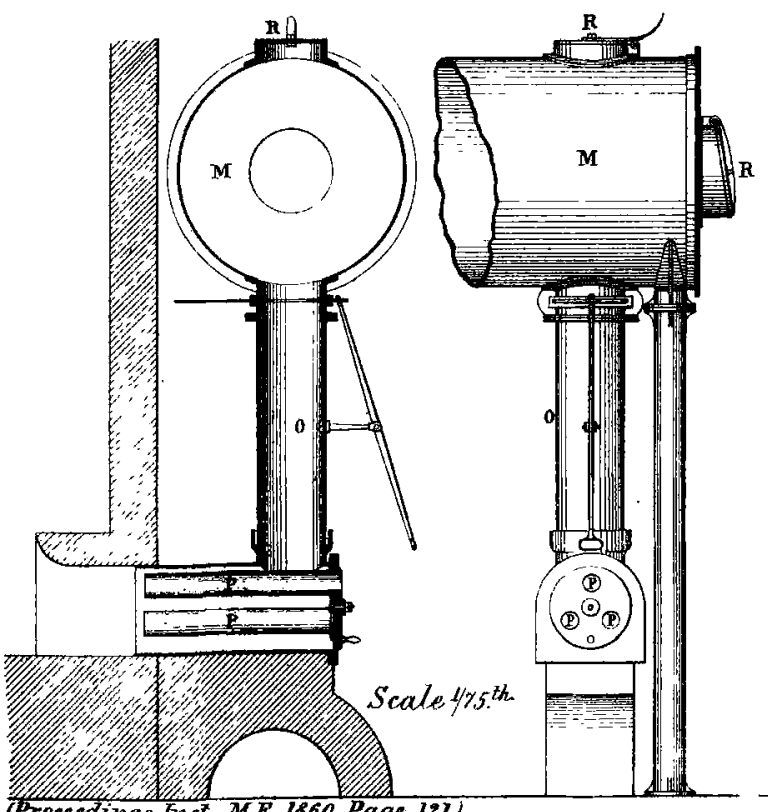

Fig. 5 .

Mode of conveying Waste Gases from Blast Fumace to Hot-Blast stores

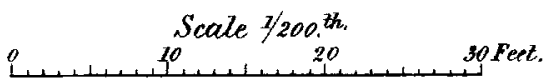
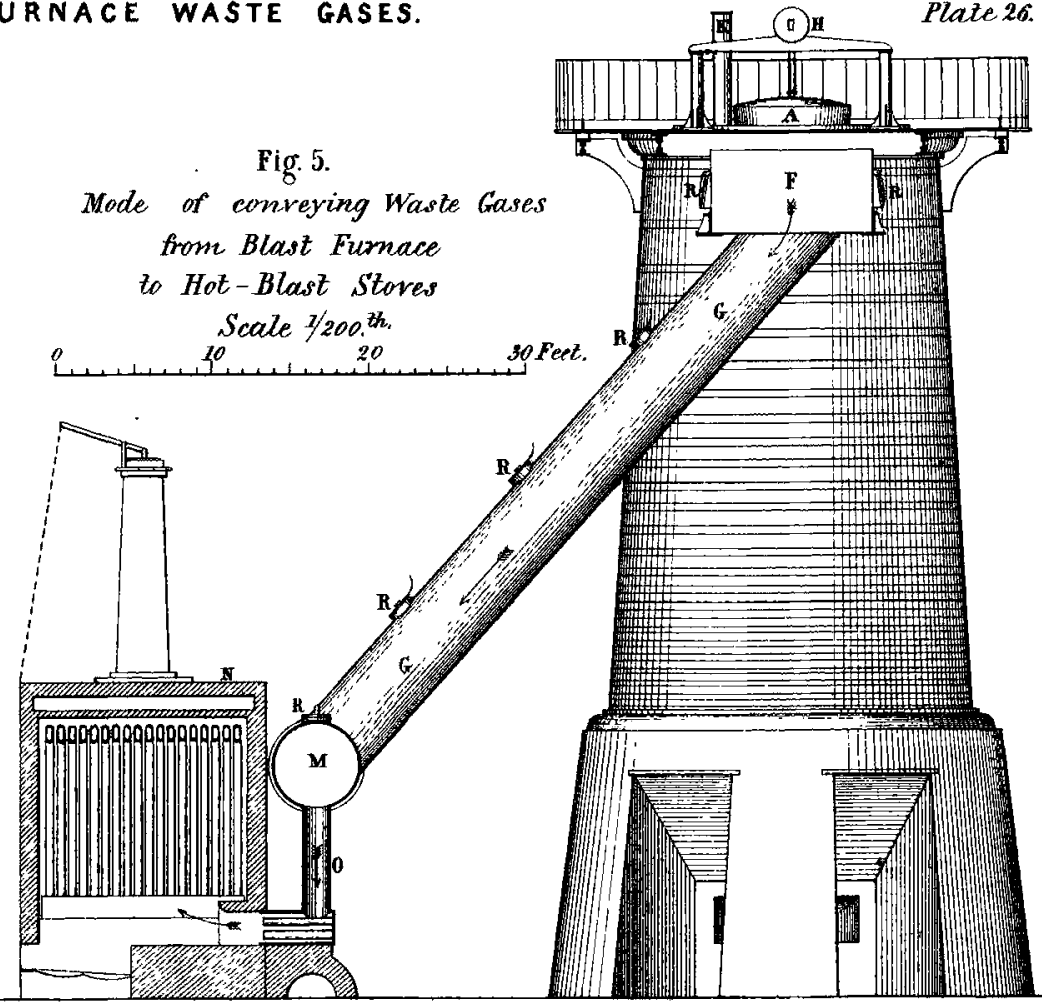